obviously conscious. He began to deteriorate to such a degree that the lack of coughing and movement rendered pneumonia likely and his life was thus very seriously at risk. At this stage it was difficult to determine the aetiology of his stupor. During an injection of intravenous diazepam a brief conversation elicited that he was well orientated and that he had delusions of worthlessness and auditory hallucinations where the other patients discussed his sins. All this was consistent with a severe psychotic, depressive stupor.

Intravenous antidepressants were started but as by the 10th post-operative day he still appeared to be deteriorating he was given ECT. Following this he was more responsive and spoke a few words. After the second treatment, although still depressed, he began to talk spontaneously and was able to sit out of bed and to eat. Oral antidepressants were substituted and he had one further ECT following which he was able to converse normally and participate in his rehabilitation. At the time of his discharge four weeks after surgery he had made a complete psychological and an almost complete physical recovery.

We believe this case is unusual in that there has been no report of a case of depressive stupor arising at such an early stage after surgery. The necessity to use ECT so soon after a major surgical procedure is also unique. A recent case study (Ries and Bokan, 1979) reported using ECT 30 days after pituitary surgery in a patient with depressive stupor where the risk of physical deteroiration was high. In some ways this case was similar to our own, but the patient had in fact suffered from a psychotic depression related to her Cushing's disease prior to surgery, unlike our patient.

Although ECT has been used for many years now in the treatment of psychiatric disorders its exact place as a therapeutic agent is still debated (Palmer, 1981). In this case, however, although the risks of ECT were probably higher than is usually the case, it does appear that it was effective and almost certainly life saving.

\section{J. Thomas}

A. Hall

Leicester Royal Infirmary,

Westcotes Hospital,

Westcotes Drive,

Leicester LE3 OQW

\section{References}

KNOX, S. J. (1961) Severe psychiatric disturbances in the post-operative period-A five year survey of Belfast Hospitals. Journal of Mental Science, 107, 1078-96.

PALMER, R. L. (ed.) (1981) Electroconvulsive Therapy: An Appraisal. Oxford: Oxford Medical Publications.

RIES, R. \& BOKAN, J. (1979) Electroconvulsive therapy following pituitary surgery. Journal of Nervous and Mental Disease, 167, 767-8.

DEAR SIR

\section{ANXIETY IN EGYPT}

In their study of anxiety in Egypt (Journal, July
$1981,139,70-3)$ Okasha and Ashour claim significant differences in some presentations, but their methodology allows for questioning the validity of their findings.

The cluster of symptoms used to diagnose anxiety was stretched beyond their definition of an 'anxiety state'. The inclusion of fugues and amnesia, dissociative and conversion symptoms, as well as specific phobias, hypochondriasis, obsessional checking and depersonalisation suggests the possibility of other neurotic disorders being present. Could it not be the case that they were studying other neurotic disorders, some of which are known to be significantly different from each other but could each include anxiety as a symptom?

Both the ICD-9 and PSE are clear about their definitions of various neurotic disorders which are often mutually exclusive. However, patients can still present with mixed neuroses but then the most prominent features will favour a specific diagnosis. Specific phobias, fugues and amnesia, dissociative and conversion symptoms are more expected to point to a diagnosis other than anxiety.

To diagnose anxiety, I understand, the authors applied 52 out of the 140 symptoms included in the PSE symptom list. They assessed symptoms like organic impairment of memory, subjective euphoria, ideomotor pressure, and grandiose ideas and actions. Some of these latter symptoms do not appear under any of the PSE syndromes of neurotic disorder.

Anxiety may present as a symptom, trait or state when the implications for treatment and outcome may differ. A comment on management and prognosis might have clarified the situation further.

All Saints Hospital,
Lodge Road,
Birmingham B18 550

E. A. Hammad

\section{ABNORMAL INVOLUNTARY MOVEMENTS IN THE ELDERLY}

DEAR SIR,

A. J. Blowers and colleagues (Journal, October $1981,139,363-4)$ claim their study "has shown that in a group of elderly subjects ... antipsychotic drugs ... increase the risk of developing dyskinesias". Surely not. What their study has shown is that those elderly subjects who had been selected for treatment with antipsychotic drugs had a significantly higher prevalence of abnormal involuntary movements than those who had not been so selected.

E. R. Squibb,

A. A. SCHIFF

141-149 Staines Road, Hounslow TW3 3JA 